\title{
International Outcome Inventory for Hearing Aids: Data From a Large Swedish Quality Register Database
}

Stig Arlinger, Peter Nordqvist and Marie Öberg

The self-archived postprint version of this journal article is available at Linköping University Institutional Repository (DiVA):

http:// urn.kb.se/ resolve?urn=urn:nbn:se:liu:diva- 144000

N.B.: When citing this work, cite the original publication.

Arlinger, S., Nordqvist, P., Öberg, M., (2017), International Outcome Inventory for Hearing Aids: Data From a Large Swedish Quality Register Database, American J ournal of Audiology, 26(3), 443-450.

https://doi.org/ 10.1044/2017_AJA-16-0123

Original publication available at:

https:// doi.org/ 10.1044/2017 AJ A-16-0123

Copyright: American Speech-Language-Hearing Association

http:/ / www.asha.org/ default.htm 


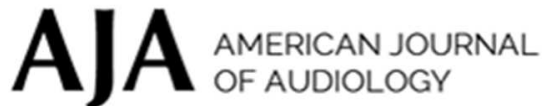

\section{HEAL 2016 Special Issue: IOI-HA: Data From a Large Swedish Quality Register Database}

\begin{tabular}{|r|l|}
\hline Journal: & The American Journal of Audiology \\
\hline Manuscript ID & AJA-16-0123.R1 \\
\hline Manuscript Type: & Research Article \\
\hline Date Submitted by the Author: & 15-Apr-2017 \\
\hline Complete List of Authors: & $\begin{array}{l}\text { Arlinger, Stig; Linköping university, Department of Clinical and } \\
\text { Experimental Medicine, Technical Audiology } \\
\text { Nordqvist, Peter; Forskningsinstitutet Hörselbron, Department of Speech } \\
\text { Music and Hearing, KTH } \\
\text { Öberg, Marie; Department of Clinical and Experimental Medicine, }, \text { Technical } \\
\text { Audiology,Faculty of Health Sciences, Linköping University, Department of } \\
\text { Otorhinolaryngology in Linköping, Anaesthetics, Operations and Specialty } \\
\text { Surgery Center, County Council of Östergötland, Sweden }\end{array}$ \\
\hline Keywords: & $\begin{array}{l}\text { Auditory rehabilitation, Amplification or hearing aids, Outcomes, } \\
\text { Assessment }\end{array}$ \\
\hline
\end{tabular}




\section{HEAL 2016 Special Issue: IOI-HA: Data From a Large Swedish Quality Register Database}

Stig Arlinger, ${ }^{\mathrm{a}, \mathrm{b}}$ Peter Nordqvist, ${ }^{\mathrm{c}}$ and Marie Öberg ${ }^{\mathrm{a}, \mathrm{b}, \mathrm{d}}$

${ }^{a}$ Division of Technical Audiology, Department of Clinical and Experimental Medicine, Linköping University, Linköping, Sweden,

${ }^{\mathrm{b}}$ Linnaeus Centre HEAD, Swedish Institute for Disability Research, Department of Behavioural Sciences and Learning, Linköping University, Linköping, Sweden,

${ }^{c}$ Research Institute Hörselbron, School of Computer Science and Communication, Royal Institute of Technology, Stockholm, Sweden

${ }^{\mathrm{d}}$ Department of Otorhinolaryngology in Linköping, Anaesthetics, Operations and Specialty Surgery Centre, Region Östergötland, Sweden

Correspondence to Stig Arlinger: stig.arlinger@liu.se

Disclosure: The authors have declared that no competing interests existed at the time of publication 


\begin{abstract}
Purpose: The purpose of this study was to analyze a data-base of completed IOI-HA questionnaires obtained from over 100000 clients fitted with new hearing aids in Sweden during the period 2012-2016. Mean IOI-HA total scores were correlated with degree of hearing loss, unilateral vs bilateral fitting, first-time vs return clients, gender, and variation among dispensing clinics. The correlations with expectations, service quality and technical functioning of the hearing aids were also analyzed.
\end{abstract}

Method: Questionnaires containing the seven IOI-HA items as well as questions concerning some additional issues were mailed to clients 3-6 months after fitting of new hearing aids. The questionnaires were returned to and analyzed by an independent research institute.

Results: More than 100 dispensing clinics nationwide take part in this project. A response rate of 52,6\% resulted in 106631 data sets after excluding incomplete questionnaires. $46 \%$ of the responders were women, $54 \%$ men. The largest difference in mean score $(0.66)$ was found for the IOI-HA item use between return clients and first time users. Women reported significantly higher (=better) scores for item impact on others (ioth) compared to men. The subgroup bilaterally fitted reported significantly higher scores for all seven items compared to unilaterally fitted. Experienced users produced higher scores on benefit and satisfaction items whereas first-time users gave higher scores for residual problems. No correlation was found between mean IOI-HA total score and average hearing threshold level (PTA). Mean IOI-HA total scores were found to correlate significantly with perceived service quality of the dispensing center and with the technical functionality of the hearing aids.

Conclusions: When comparing mean IOI-HA total scores from different studies or between groups, differences with regard to hearing aid experience, gender, and unilateral vs bilateral fitting have to be considered. No correlation was found between mean IOI-HA total score and degree of hearing loss in terms of PTA. Thus, PTA is not a reliable predictor of benefit and satisfaction of hearing aid provision as represented by the IOI-HA items. Identification of a specific lower fence in PTA for hearing aid candidacy is therefore to be avoided. Large differences were found in mean IOI-HA total scores related to different dispensing centers. 
Over the years, several instruments have been presented to assess the quality of hearing aid fitting, e.g. COSI (Dillon \& Ginis, 1997), APHAB (Cox \& Alexander, 1995), GHABP (Gatehouse, 1999). Some of these instruments had items which were more relevant in some countries or cultural environments than in others. These issues, as discussed by Arlinger (2000), obviously represented limitations when searching for outcome measures that could be used across all barriers of culture, age, and other population sub-groups. With these aspects in mind as well as with the intent to cover all relevant aspects of the outcome of audiological rehabilitation in a minimal set of core outcome items, the International Outcome Inventory for Hearing Aids, IOI-HA, was presented in its first version in English (Cox et al. 2000).

The IOI-HA is based on seven short items - see Appendix A. They concern the use of hearing aids, the benefit perceived, remaining activity limitation, satisfaction, residual participation restriction, effect on significant others, and change in quality of life. The time frame specified for several of the items is the past two weeks. Each item is to be answered by one of five alternatives. When analyzing data, the five alternatives are translated to the digits 1-5 where 1 represents the poorest and 5 the best outcome, going from left to right on the form. The original version was in English, but very soon a large number of translations were published. The report by Cox, Stephens \& Kramer, 2002 presents an additional 20 language versions. The first Swedish version was slightly modified in 2005 in order to eliminate a risk of misunderstanding by some clients. This revised version has been used in the present study.

A number of studies have presented psychometric data for IOI-HA on populations ranging from 53 to 1653 subjects. In all studies, the responses have been based on paper versions of the IOI-HA being mailed to the participants. Most of these studies have reported psychometric characteristics of IOI-HA including correlations between responses to the seven items. Several studies have also applied factor analysis, showing that the responses can be described by two main factors. Kramer, Goverts, Dreschler, Boymans \& Festen (2002) identified factor 1 as representing use, benefit, satisfaction and quality of life, i.e. items 1, 2, 4 and 7. Factor 2 represented residual activity limitations, residual participation restrictions and impact on others, i.e. items 3, 5 and 6. Cox \&Alexander (2002) suggested that factor 1 was mainly focused on the individual's interaction with the hearing aids ("me and my hearing aids") while factor 2 was more concerned with the interaction of the individual with other people ("me and the rest of the world"). Also Brännström \& Wennerström (2010) and Jespersen, Bille \& Legarth (2014) identified the same two factors.

The Swedish quality register on hearing aid benefit is run by the Research Institute Hörselbron, which was established in 2011 and is owned by the Swedish National Association for the Hard of Hearing. The ultimate goal is to reach all hearing aid clients in Sweden, and so far approximately $70 \%$ of all new fittings are included. More than 100 dispensing centers participate, both private centers and those belonging to the public health system. The vast majority of hearing aids dispensed in Sweden are financially supported through the public health system, either fully or partially as determined by the policies of each county. The patient usually pays a nominal fee for the fitting services including follow- 
up. The services are available either through hearing centers in the public hospitals or through private hearing dispensing clinics, operating by contract with the public health authorities. Within a given county, public and private services mainly offer the same assortment of hearing aid types. Audiologists providing the services in both types of organization have the same 3-year audiology qualification offered by four medical faculties in Sweden.

The purpose of this study was to analyze this uniquely large database with IOI-HA data in terms outcome related to a number of factors. Because of its size, responses could be assessed in a number of subgroups, which were still sufficiently large to be able to verify the presence or absence of statistically significant differences. The specific aspects in focus were the correlations between mean IOI-HA total scores and degree of hearing loss, gender, unilateral vs bilateral fitting, first-time users vs return clients, and dispensing clinics.

\section{Methods}

Each third month questionnaires were sent by mail to clients aged 18 years and above who had been reported by participating clinics. The fitted hearing aids had then been in use for a period of between 3 and 6 months. In order to avoid exaggerated outcomes self- reported assessment should not be performed until at least 6-8 weeks have passed after hearing aid rehabilitation since studies have shown data to remain stable after this period (Dillon, 2012; McArdle, Chisolm, Abrams, Wilson \& Doyle, 2005). All questions were answered by paperand-pencil. The clients were asked to return the filled out questionnaires to the Research Institute Hörselbron, which is independent of the clinics responsible for fitting the hearing aids.

The questionnaire contained a total of 17 items, all to be answered in one of five alternatives, where the alternative to the far left is the most negative and the alternative to the far right the most positive. In addition to the seven IOI-HA items there were five items concerning how satisfied the client was with reception, information, and participation in the process, and four questions related to function and technology - see Appendix B. One additional item concerned expectations regarding the hearing aid rehabilitation process. The answers from the subjective questionnaire were treated as values on an interval scale with uniform distance between the five alternatives. This is the most frequently used method when analyzing outcome measures. From that standard statistics can be calculated, e.g. mean and standard deviation. Correlation coefficients were calculated using Spearman's rank correlation. Statistical significance (p-value) was calculated using Mann-Whitney U-test.

The subjective answers from the respondents were complemented with objective data, e.g. pure tone audiogram, age, gender, first-time vs experienced user, and uni- vs. bilateral fitting. Average pure tone hearing loss, PTA, was calculated as the average of hearing threshold levels at $0.5,1,2$ and $4 \mathrm{kHz}$ for left and right ears together. Since the vast majority of subjects had essentially symmetrical sensorineural hearing losses there was no reason to separate between worse and better ears. PTA-data were available for 34889 subjects. 


\section{Results}

\section{$\underline{\text { Response rate }}$}

Since 2012 an accumulated number of 204350 questionnaires have been sent out resulting in 107518 answers, i.e. a response rate of 52.6\%. Data sets containing missing IOI-HA data were excluded from the study, resulting in a total number of 106631 subjects included. This is approximately half of all fittings performed in Sweden during that period. Of data sets included, $46 \%$ came from women. Their mean age was 74.2 years whereas for men it was 73.3. Men dominated in the age range 60-79 years, while women dominated at younger and older ages. There were no significant differences in age distribution between responders and non-responders.

No reminders were sent to non-responders. The non-response analysis showed small differences between respondents and non-respondents regarding age and gender. Men were somewhat better than women in responding - 54.0 versus $50.9 \%$. In terms of age, the nonresponders differed very little from the responders; the largest difference was among men, where responders were on average 16 months older than non-responders.

Cronbach's alpha was calculated for the complete data set of IOI-HA scores from the 106 631 subjects. A value of 0.813 was found, indicating that the mean IOI-HA score has a good internal consistency when used to measure self-reported outcome after hearing aid fitting. For factor 1 the corresponding value was 0.802 and for factor 2 it was 0.796 . These data agree with those found by Brännström \& Wennerström (2010) and Öberg, Lunner \& Andersson (2007).

\section{$\underline{\text { Unilateral/bilateral fittings and gender differences }}$}

Table 1 shows the mean values and standard deviations of the seven IOI-HA items as well as for the total score for all responses received during the years 2012-2016. Clients with bilateral fittings reported higher scores on all seven items compared to those with unilateral fittings. Women tended to report slightly higher scores than men with the largest difference for item 6 concerning influence on others by their hearing difficulties.

The table also shows in the top two rows mean age and mean PTA for the total group as well as for the subgroups. In addition, mean values and standard deviations for the responses to the additional ten questions regarding technical functionality, service quality and expectations are included.

\section{$\underline{\text { Return clients versus first time clients. }}$}

Return clients reported longer daily use, more benefit and satisfaction and higher quality of life than first time clients. However, they report more remaining difficulties and limitations as well as more negative effects on others by their hearing difficulties.

\section{(Table 1 here)}

IOI-HA versus degree of hearing loss. 
When analyzing the correlation between mean IOI-HA total scores and average fourfrequency $(0.5 / 1 / 2 / 4 \mathrm{kHz})$ hearing threshold levels (PTA) for the clients that were fitted bilaterally and for whom PTA-values were available, the correlation was found to be virtually zero. For a linear correlation, the correlation coefficient is -0.015 . Figure 1 illustrates the relationship including a curve representing a second order polynomial regression fit with a slightly concave downward shape. There are obviously clients with very mild hearing losses that reported very high mean scores. For more severe losses with PTA exceeding $80 \mathrm{~dB}$ HL the total scores tended to be somewhat lower. When analyzing first time users and return clients separately, the correlation with PTA remains low: $r=-0.004(p<0.001)$ for first time users and $r=-0.038(p<0.001)$ for return clients.

(Figure 1 here)

The two main factors of IOI-HA identified by Cox \&Alexander (2002) as factor 1, called "me and me hearing aids" (items 1, 2, 4 and 7 concerning use, benefit, satisfaction and influence on quality of life), and factor 2, called "me and the rest of the world" (items 3, 5 and 6), concerning residual limitations and participation restrictions, and impact on others represent somewhat different aspects of the outcome of hearing aid fitting and may have different correlations with the clients' degree of hearing loss. Figure 2 shows the average scores of factor 1, i.e. items 1, 2, 4 and 7, versus PTA with a second order polynomial regression curve added. For these four items separately, the total scores were lower for clients with only mild or moderate degree of hearing loss, which most likely reflects fewer hours of daily use.

(Figure 2 here)

Factor 2, on the other hand, shows a different relation to PTA as illustrated in Figure 3. The second order polynomial regression curve shows decreasing mean values for these three items for clients with more severe hearing loss. This comes as no surprise since with more severe hearing loss more residual limitations and participation restrictions are likely to be present.

(Figure 3 here)

Expectations, service quality and technical functioning.

In addition to IOI-HA, the clients answered one question on expectations on the rehabilitation before the first visit. The responses to this question showed a very low correlation to mean IOI-HA total scores $(\mathrm{r}=0.15, \mathrm{p}<\mathrm{e}-15)$. The five additional questions related to the service quality in terms of dispenser's attitude, information and support, the client's participation in selection of devices and the fitting procedure, were analyzed in terms of the mean scores in relation to the mean IOI-HA total scores. The correlation was statistically significant $(\mathrm{r}=0.46$, $\mathrm{p}<\mathrm{e}-16$ ) - the higher the mean scores on the service quality, the higher the mean total scores on IOI-HA. The final group of four additional questions was more focused on technical functions: uncomfortably loud sounds, acoustic feedback problems, perceived sound quality, and benefit in noisy environments. The correlation between this technical factor and mean IOI-HA total scores was also statistically significant $(\mathrm{r}=0.48, \mathrm{p}<\mathrm{e}-16)$. 
Variation between dispensing clinics.

The validation of hearing aid fitting performed in a large number of clinics under relatively comparable conditions and with the validation performed by a neutral body offers a unique possibility to compare outcome from different dispensers. Figure 4 shows the distribution of mean IOI-HA total scores based on clients from 95 different private dispensing clinics. The number of clients fitted in each clinic during the limited time period studied varied of course, but the average was 530 clients. The majority of the clinics are very close but the difference between the extremes is surprisingly large. It corresponds to more than three times the difference in mean score for clients that received bilateral fitting compared to those receiving unilateral fitting.

\section{(Figure 4 here)}

\section{Discussion}

The present study is unique in terms of its size with over 100000 responses obtained during the period 2012 - 2016. Thus, they represent the experience of people fitted with modern hearing aids based on digital technology. The fact that all questionnaires were returned to a neutral research institute and not to the dispensing organization is another advantage, which makes the present study differ from most other published reports. The clients are guaranteed secrecy, and reports from the database are in statistical terms only with no identification of individual responses.

\section{$\underline{\text { Response rate }}$}

The overall response rate in the present study was $52.6 \%$. It is obviously an open question whether the responders are more or less satisfied with their hearing aids or if other aspects influence their decision to respond. However, this possible response bias has no effect in comparisons, e.g. between clinics or regions. Öberg, Lunner \& Andersson (2007) found in their study that clients who were frequent hearing aid users also showed a higher sense of coherence and lower degree of depression compared to those who reported less use of their aids, i.e. non-auditory psychological factors may also be involved.

\section{Overall IOI-HA scores}

When comparing the average scores in the present study with those of the two largest earlier studies (Hickson, Clutterbuck \& Khan, 2010, and Liu, Zhang, Liu, Chen, Han \& Zhang, 2011) with 1653 and 1049 subjects, respectively, items 1 and 7 are very close, the scores for items 2, 4 and 5 are somewhat higher in our material, while the scores on items 3 and 6 are slightly lower. Compared to the two earlier Swedish studies (Brännström \& Wennerström, 2010, and Öberg, Lunner \& Andersson, 2007) the present study shows somewhat higher scores on item 1 (Use), approximately the same on item 7 (Quality of life) but slightly lower scores on items 2, 3, 4, 5 and 6. However, those studies were relatively small, based on 224 and 162 clients, respectively.

$\underline{\text { Bilateral vs unilateral fitting }}$ 
Clients who received bilateral fitting of hearing aids gave significantly higher scores on all seven items compared to clients with unilateral fittings (Table 1). The average differences were largest for items $1,2,4$ and 7 by $0.16-0.21$, i.e. for factor 1 , which relates to "me and my hearing aids" according to Cox \& Alexander (2002). For factor 2, items 3, 5 and 6, related to "me and the rest of the world", the average differences were $0.10-0.12$. The difference in mean total score was $0.16(\mathrm{p}=\mathrm{e}-16)$, a difference that could be considered as clinically significant. The smallest possible difference in mean scores between two clients is $1 / 7$ or about 0.14 , i.e. only one of the seven sub-scales differs by one unit along the range 1-5. On average, the clients in the binaural group have answered at least one unit better on one of the sub-scales compared to the unilateral group. Probably even smaller differences may be considered as clinically relevant, however the unilateral/bilateral difference is easy to interpret. This agrees with Smith, Noe \& Alexander (2009), who administered IOI-HA on two occasions with two weeks interval to a group of 131 hearing aid users. Their findings indicated that for any item on the IOI-HA, there is a 95 percent chance that an observed change of one response unit between two test sessions reflects a true change in outcome for a given domain.

\section{$\underline{\text { IOI-HA vs degree of hearing loss }}$}

Our finding of no significant correlation between degree of hearing loss and mean IOI-HA total scores is interesting since it may be considered counterintuitive. The results from previously published studies have been ambiguous. The earlier Swedish study by Brännström \& Wennerström (2010), based on 224 subjects, showed that PTA was not associated with any of the IOI-HA items with one exception - a significant positive correlation with item 1 (hours of use). Jespersen, Bille \& Legarth (2014) found in their correlation analysis a weak but statistically significant positive correlation between PTA $(0.25,0.5,1,2,4 \mathrm{kHz})$ and item 1 (hours of use) and item 4 (satisfaction). A weak yet statistically significant negative correlation was found between PTA and item 5 (residual participation restrictions) and item 6 (impact on others). In the present material, we can see a small positive correlation for factor 1 (items 1, 2, 4 and 7) and a somewhat larger negative correlation for factor 2 (items 3, 5 and 6) with PTA. These findings suggest that the degree of hearing loss in terms of four-frequency PTA cannot reliably predict the success of hearing aid fitting. Our findings agree with Vestergaard Knudsen, Öberg, Nielsen, Naylor \& Kramer (2010), who concluded in their review of 39 published papers "that self-reported auditory difficulty is highly important in aural rehabilitation, possibly more important than objective hearing sensitivity, which showed less consistent effects on outcomes." It comes as no surprise that clients with a mild or moderate degree of hearing loss are likely to use the hearing aids fewer hours per day on average, nor is it surprising that clients with a more severe hearing loss will have more of residual problems. Still, it is clear that clients across the whole range of hearing loss may report high degrees of benefit and satisfaction with their hearing aids. These findings are in our opinion strong arguments against any lower fence in terms of hearing loss as a condition for access to hearing aids.

First-time users vs return clients 
Overall, the present study showed somewhat higher mean scores for the IOI-HA from experienced clients compared to first-time users. When analyzing the data for these two groups with regard to the two factors in the IOI-HA questionnaire, experienced users gave higher scores in the use/benefit/ satisfaction domain (factor 1) but lower scores for residual problems (factor 2). These differences are obviously related to the experienced users having more severe hearing loss as shown in Table 1.

\section{$\underline{\text { Gender differences }}$}

The differences between men and women were in general small except for item 6 (Table 1) "How much do you think other people were bothered by your hearing difficulties?" This might be related to women in general being more socially active than men. Vesterager \& Salomon (1991) found a difference between gender and communication strategies, where pretending and withdrawal attitudes were 2-3 times more common for men.

$\underline{\text { Service quality, technical functionality and variation among dispensing clinics }}$

The significant correlations between mean IOI-HA total scores and factors related to perceived service quality and to technical functions of the instruments are important outcomes of the present study and to the issue of today's changing hearing health care delivery models. The data show clearly that a client who was received by the dispensing center as an important partner in the selection and fitting procedure was likely to report higher outcome scores. Likewise, a client whose hearing aids provided good sound quality with no acoustic feedback and acceptable maximum output levels was even more likely to report higher outcome scores. These two aspects of hearing aid fitting may well be related to the large variation between different dispensing clinics illustrated in Figure 4. The professional attitude of the dispenser as well as his/her experience and skills in selecting the best hearing instruments and making optimal use of the programming software are basic parameters that will have strong influence on the client's benefit and satisfaction.

Over-the-counter (OTC) hearing aids or personal sound amplifying products, PSAP, may provide a simpler starting point for someone with a mild hearing loss and may reduce the still prevailing stigma related to hearing aids. On the other hand, the distribution model without the normal professional support provided by an audiologist is likely to result in less satisfied users. Humes, Rogers, Quigley, Main, Kinney \& Herring (2017) in a very recent study compared OTC with audiology best practices. They found that the OTC service delivery yielded only slightly poorer outcomes but significantly lower satisfaction and percentage of subjects likely to purchase hearing aids after the trial. Future delivery models combining OTC instruments with remote fitting/adjustments and support over Internet on demand may open new avenues towards wider acceptance of and satisfaction with hearing instruments.

\section{Conclusions}

A very large Swedish database of IOI-HA has been analyzed. The results show that subjects with bilaterally fitted hearing aids gave higher scores than those with unilateral fittings. Experienced users also produced higher scores on benefit and satisfaction items (factor 1) 
whereas first-time users gave higher scores for residual problems (factor 2). When comparing IOI-HA scores from different studies or between groups, differences in these three parameters should be considered. No correlation was found between mean IOI-HA total scores and degree of hearing loss in terms of PTA. Identification of a specific lower fence for hearing aid candidacy and prediction of reliable satisfaction is therefore not possible.

A standardized validation measure such as the IOI-HA is a tool that may be used to identify clients that need special attention in order to be successful hearing aid users. In the application illustrated in this report where a large number of dispensing centers provide outcome data from their clients to be analyzed by a neutral service center, the system will be able to give the various centers valuable feedback, allowing them to improve their services for the benefit of their clients.

\section{Acknowledgement}

We thank all counties in Sweden that participated in the quality register, The Swedish Association of Hard of Hearing for contributing with a research grant, and the board of the quality register for valuable input to the project.

\section{References}

Brännström, K.J., \& Wennerström, I. (2010). Hearing Aid Fitting Outcome: Clinical Application and Psychometric Properties of a Swedish Translation of the International 
Outcome Inventory for Hearing Aids (IOI-HA). Journal of the American Academy of Audiology, 21(8), 512-521.

Cox, R.M., \& Alexander G.C. (1995). The abbreviated profile of hearing aid benefit. Ear and Hearing, 16(2), 176-186.

Cox, R., Hyde, M., Gatehouse, S.,, Noble, W., Dillon, H., Bentler, R.,...Hallberg, L. (2000). Optimal outcome measures, research priorities, and international cooperation. Ear and Hearing, 21(4 Suppl), 106S-115S.

Cox, R.M., \& Alexander, G.C. (2002). The International Outcome Inventory for Hearing Aids (IOI-HA): psychometric properties of the English version. International Journal of Audiology, 41(1), 30-35.

Cox, R.M., Stephens, D., \& Kramer, S.E. (2002). Translations of the International Outcome inventory for Hearing Aids (IOI-HA). International Journal of Audiology, 41(1), 3-26.

Dillon, H., \& Ginis, J.A. (1997). The Client-Oriented Scale of Improvement (COSI) and its relationship to several other measures of benefit and satisfaction provided by hearing aids. Journal of the American Academy of Audiology, 8(1), 27-43.

Dillon, H. (2012). Hearing Aids (2nd ed.). Sydney: Boomerang Press; Stuttgart: Thieme (p. 424).

Gatehouse, S. (1999). A self-report outcome measure for the evaluation of hearing aid fittings and services. Health Bulletin (Edinb), 57(6), 424-436.

Hickson, L., Clutterbuck, S., \& Khan, A. (2010). Factors associated with hearing aid fitting outcomes on the IOI-HA. International Journal of Audiology, 49(8), 586-595.

Humes, L.E., Rogers, S.E., Quigley, T.M., Main, A.K., Kinney, D.L. \& Herring, C. (2017). The Effects of Service-Delivery Model and Purchase Price on Hearing-Aid Outcomes in Older Adults: A Randomized Double- Blind Placebo-Controlled Clinical Trial. American Journal of Audiology, 26(1), 53-79.

Jespersen, C.T., Bille, M., \& Legarth, J.V. (2014). Psychometric properties of a revised Danish translation of the international outcome inventory for hearing aids (IOI-HA). International Journal of Audiology, 53(5), 302-308.

Kramer, S.E., Goverts, S.T., Dreschler, W.A., Boymans, M., \& Festen J.M. (2002). International Outcome Inventory for Hearing Aids (IOI-HA): results from The Netherlands. International Journal of Audiology, 41(1), 36-41.

Liu, H., Zhang, H., Liu, S., Chen, X., Han, D. \& Zhang, L. (2011). International outcome inventory for hearing aids (IOI-HA): results from the Chinese version. International Journal of Audiology, 50(10), 673-678. 
McArdle, R, .Chisolm, T.H., Abrams, H.B., Wilson, R.H. \& Doyle, P.J. (2005).The WHODAS II: measuring outcomes of hearing aid intervention for adults. Trends in Amplification 9(3):127-143.

Smith, S.L., Noe, C.M., \& Alexander, G.C. (2009). Evaluation of the International Outcome Inventory for Hearing Aids in a veteran sample. Journal of the American Academy of Audiology, 20(6), 374-380.

Vesterager, V., \& Salomon, G. (1991). Psychosocial aspects of hearing impairment in the elderly. Acta Otolaryngologica Suppl. 476, 215-220.

Vestergaard Knudsen,L., Öberg,M., Nielsen,C., Naylor,G. \& Kramer,S. (2010). Factors influencing help seeking, hearing aid use and satisfaction with hearing aids: A review of the literature. Trends in Amplification, 14(3), 127-154.

Öberg, M., Lunner, T., \& Andersson G. (2007). Psychometric evaluation of hearing specific self-report measures and their associations with psychosocial and demographic variables. Audiological Medicine, 5(3), 188-199.

Legends for figures:

Figure 1. Mean IOI-HA total score as a function of average hearing thresholds, PTA, $(0.5 / 1 / 2 / 4 \mathrm{kHz})$ for both ears. The curve represents the second order polynomial regression line. 
Figure 2. Mean IOI-HA total scores for items 1, 2, 4 and 7 (factor 1) as function of average hearing thresholds, PTA, for both ears. The curve represents the second order polynomial regression line.

Figure 3. Mean IOI-HA total scores for items 3, 5 and 6 (factor 2) as function average hearing thresholds, PTA, for both ears. The curve represents the second order polynomial regression line.

Figure 4. Distribution of average mean IOI-HA total scores for 95 different private dispensing centers. 
Total Outcome (IOI-HA) as function of PTA $\mathrm{N}=34889$, Bilateral fittings

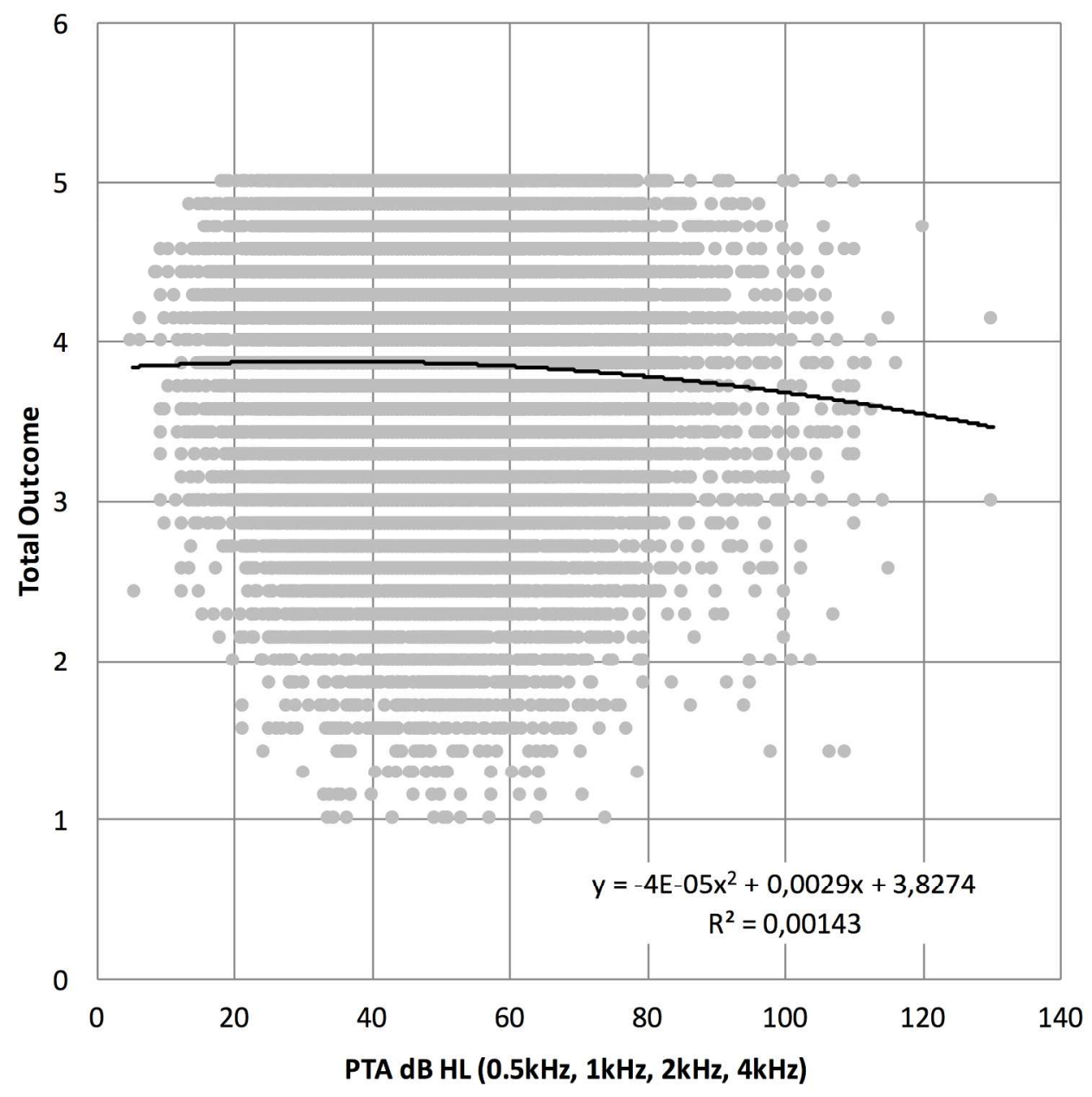




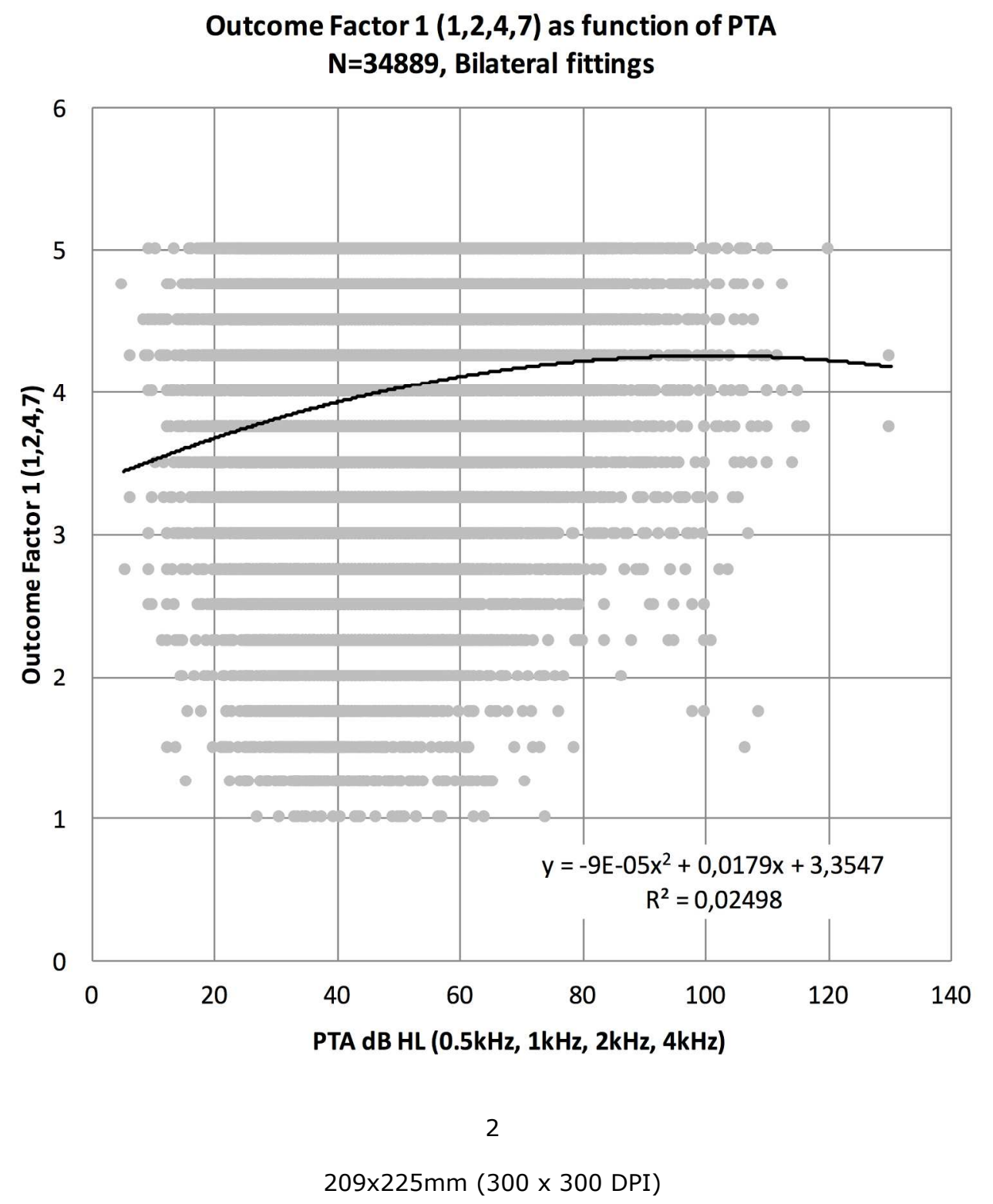


Outcome Factor $2(3,5,6)$ as function of PTA $\mathrm{N}=34889$, Bilateral fittings

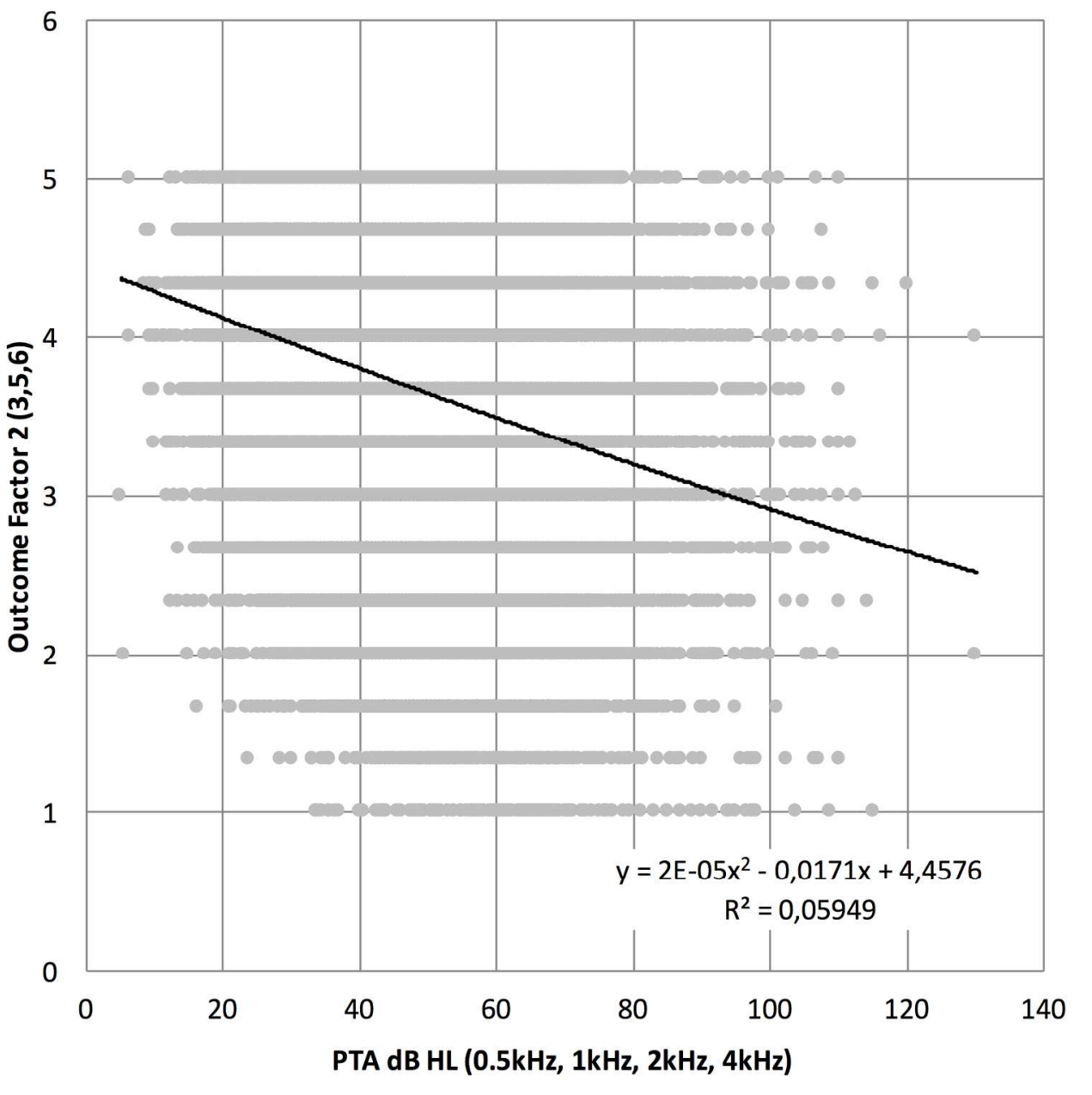




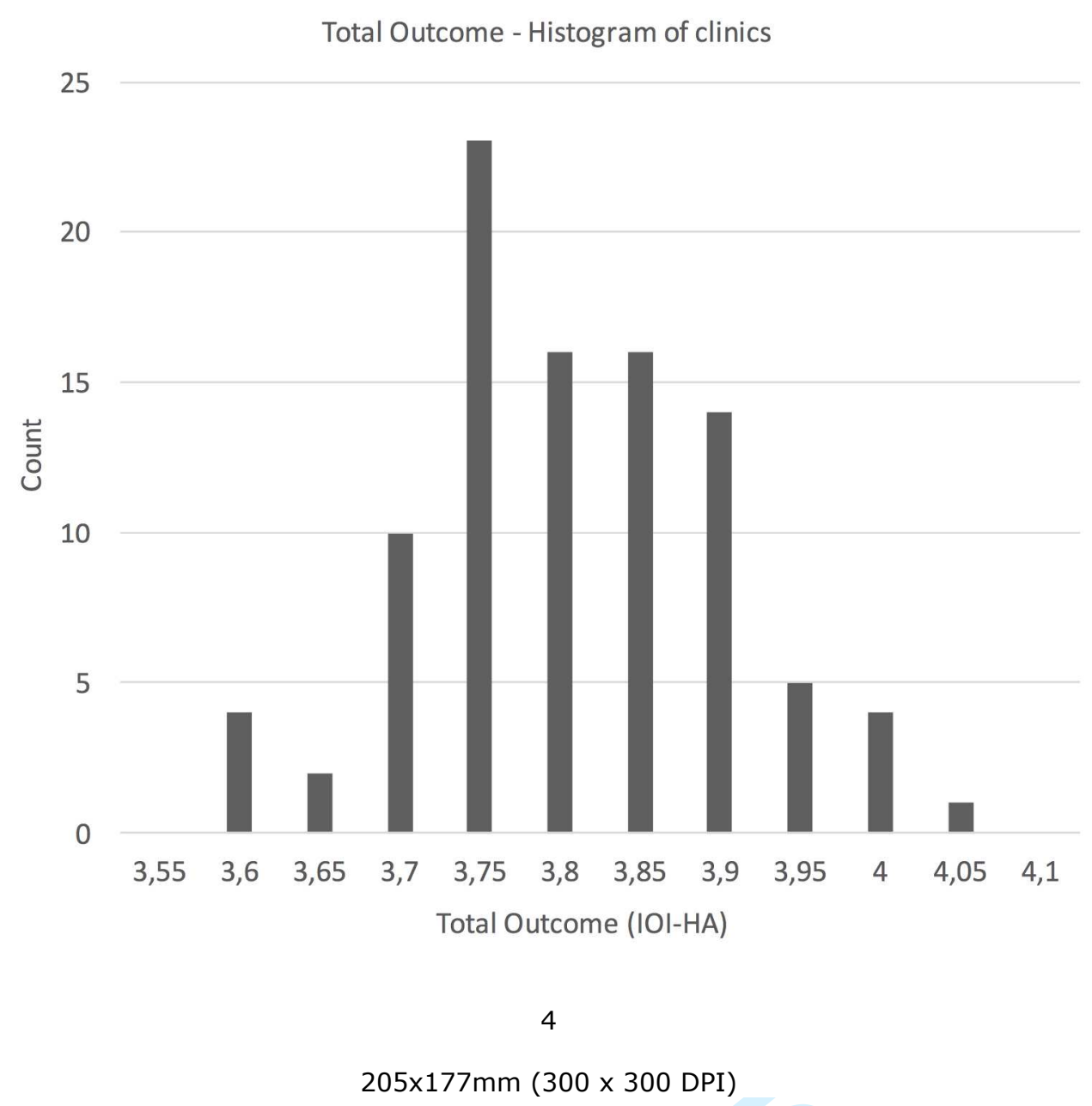


Table 1: IOI-HA scores as mean values and standard deviations. Total Outcome represents the mean IOI-HA total score. The table also shows mean values for age and average hearing thresholds (PTA) as well as means and standard deviations for the responses to questions about technical functioning, service quality and expectations.

\begin{tabular}{|c|c|c|c|c|c|c|c|c|c|c|c|c|c|c|c|}
\hline \multirow[t]{2}{*}{ Item no } & & \multicolumn{2}{|c|}{ Total } & \multicolumn{2}{|c|}{ Male } & \multicolumn{2}{|c|}{ Female } & \multicolumn{2}{|c|}{ Unilateral } & \multicolumn{2}{|c|}{ Bilateral } & \multicolumn{2}{|c|}{ Return Client } & \multicolumn{2}{|c|}{ First Time } \\
\hline & & $\mathbf{N}$ & 106631 & $\mathbf{N}$ & 57448 & $\mathbf{N}$ & 49183 & $\mathbf{N}$ & 19996 & $\mathbf{N}$ & 86138 & $\mathbf{N}$ & 63857 & $\mathbf{N}$ & 41188 \\
\hline & Mean age & 73,7 & & 73,3 & & 74,2 & & 74,3 & & 73,5 & & 74,9 & & 71,5 & \\
\hline & Mean PTA & 48,2 & & 48,0 & & 48,5 & & 52,4 & & 47,2 & & 52,4 & & 41,8 & \\
\hline & & Mean & Std & Mean & Std & Mean & Std & Mean & Std & Mean & Std & Mean & Std & Mean & Std \\
\hline & Total Outcome & 3,82 & 0,73 & 3,80 & 0,71 & 3,84 & 0,75 & 3,69 & 0,76 & 3,85 & 0,71 & 3,85 & 0,71 & 3,79 & 0,75 \\
\hline Item 1 & Use & 4,10 & 1,06 & 4,08 & 1,08 & 4,13 & 1,03 & 3,95 & 1,12 & 4,14 & 1,04 & 4,37 & 0,91 & 3,71 & 1,15 \\
\hline Item 2 & Benefit & 3,86 & 1,02 & 3,86 & 1,00 & 3,85 & 1,04 & 3,70 & 1,07 & 3,89 & 1,00 & 3,96 & 1,00 & 3,71 & 1,03 \\
\hline Item 3 & RAL & 3,31 & 1,06 & 3,30 & 1,04 & 3,33 & 1,09 & 3,23 & 1,09 & 3,34 & 1,05 & 3,17 & 1,06 & 3,53 & 1,01 \\
\hline Item 4 & Sat & 4,09 & 1,04 & 4,08 & 1,04 & 4,10 & 1,04 & 3,92 & 1,11 & 4,13 & 1,01 & 4,21 & 0,98 & 3,92 & 1,09 \\
\hline Item 5 & RPR & 4,00 & 1,03 & 3,98 & 1,01 & 4,02 & 1,06 & 3,90 & 1,09 & 4,02 & 1,01 & 3,87 & 1,06 & 4,21 & 0,94 \\
\hline Item 6 & loth & 3,71 & 1,08 & 3,65 & 1,06 & 3,79 & 1,09 & 3,63 & 1,11 & 3,73 & 1,07 & 3,55 & 1,08 & 3,97 & 1,02 \\
\hline \multirow[t]{2}{*}{ Item 7} & QoL & 3,72 & 0,99 & 3,71 & 0,96 & 3,72 & 1,03 & 3,59 & 1,02 & 3,75 & 0,99 & 3,81 & 1,00 & 3,58 & 0,97 \\
\hline & Technical & 3,73 & 0,76 & 3,72 & 0,74 & 3,74 & 0,78 & 3,70 & 0,80 & 3,74 & 0,75 & 3,67 & 0,76 & 3,83 & 0,74 \\
\hline Item 8 & Unacceptably loud & 4,01 & 0,94 & 4,00 & 0,92 & 4,02 & 0,97 & 4,01 & 0,97 & 4,01 & 0,94 & 4,00 & 0,94 & 4,03 & 0,94 \\
\hline Item 9 & Feedback & 3,96 & 1,01 & 3,93 & 0,99 & 3,99 & 1,04 & 3,91 & 1,03 & 3,97 & 1,00 & 3,86 & 1,03 & 4,12 & 0,96 \\
\hline Item 10 & Sound quality & 3,62 & 0,99 & 3,64 & 0,98 & 3,60 & 1,01 & 3,50 & 1,05 & 3,65 & 0,98 & 3,59 & 1,00 & 3,67 & 0,98 \\
\hline \multirow[t]{2}{*}{ Item 11} & Speech in noise & 2,89 & 1,21 & 2,91 & 1,19 & 2,86 & 1,23 & 2,72 & 1,22 & 2,92 & 1,20 & 2,77 & 1,20 & 3,08 & 1,19 \\
\hline & Service quality & 4,18 & 0,71 & 4,17 & 0,68 & 4,18 & 0,74 & 4,09 & 0,74 & 4,20 & 0,70 & 4,17 & 0,71 & 4,20 & 0,71 \\
\hline Item 12 & Contact & 4,51 & 0,73 & 4,51 & 0,72 & 4,51 & 0,75 & 4,46 & 0,77 & 4,52 & 0,72 & 4,47 & 0,75 & 4,56 & 0,70 \\
\hline Item 13 & Information & 4,38 & 0,80 & 4,38 & 0,78 & 4,37 & 0,82 & 4,32 & 0,83 & 4,39 & 0,79 & 4,33 & 0,82 & 4,45 & 0,76 \\
\hline Item 14 & Participation & 3,92 & 0,88 & 3,89 & 0,86 & 3,95 & 0,90 & 3,85 & 0,90 & 3,94 & 0,87 & 3,89 & 0,88 & 3,98 & 0,87 \\
\hline Item 15 & Unilateral vs bilateral & 3,84 & 1,22 & 3,85 & 1,17 & 3,84 & 1,27 & 3,67 & 1,28 & 3,88 & 1,20 & 3,91 & 1,17 & 3,74 & 1,28 \\
\hline Item 16 & Good listener & 4,24 & 0,83 & 4,23 & 0,81 & 4,24 & 0,86 & 4,15 & 0,87 & 4,26 & 0,82 & 4,23 & 0,84 & 4,26 & 0,82 \\
\hline Item 17 & Expectations & 3,48 & 0,69 & 3,46 & 0,67 & 3,50 & 0,70 & 3,40 & 0,72 & 3,49 & 0,68 & 3,50 & 0,69 & 3,44 & 0,68 \\
\hline
\end{tabular}


Appendix A

\section{INTERNATIONAL OUTCOME INVENTORY - HEARING AIDS (IOI-HA)}

1. Think about how much you used your present hearing aid(s) over the past two weeks. On an average day, how many hours did you use the hearing aid(s)?

$\begin{array}{ccccc}\text { None } & \text { less than } & 1 \text { to } 4 & 4 \text { to } 8 & \text { more than } 8 \\ & 1 \text { hour a day } & \text { hours a day } & \text { hours a day } & \text { hours a day }\end{array}$

2. Think about the situation where you most wanted to hear better before you got your present hearing aid(s). Over the past two weeks, how much has the hearing aid helped in that situation?

$\begin{array}{ccccc}\text { helped } & \text { helped } & \text { helped } & \text { helped } & \text { helped } \\ \text { not at all } & \text { slightly } & \text { moderately } & \text { quite a lot } & \text { very much } \\ \square & \square & \square & \square & \square\end{array}$

3. Think again about the situation where you most wanted to hear better. When you use your present hearing aid(s), how much difficulty do you STILL have in that situation?
very much
quite a lot
moderate
slight
no
difficulty
difficulty
difficulty
difficulty
difficulty

4. Considering everything, do you think your present hearing aid(s) is worth the trouble? not at all moderately quite a lot worth very much worth worth it worth it worth it it it

5. Over the past two weeks, with your present hearing aid(s), how much have your hearing difficulties affected the things you can do?

affected very much affected quite a lot

\section{affected} moderately affected

slightly affected not at all

6. Over the past two weeks, with your present hearing aid(s), how much do you think other people were bothered by your hearing difficulties?

$\begin{array}{ccccc}\text { bothered } & \text { bothered } & \text { bothered } & \text { bothered } & \text { bothered } \\ \text { very much } & \text { quite a lot } & \text { moderately } & \text { slightly } & \text { not at all } \\ \square & \square & \square & \square & \square\end{array}$

7. Considering everything, how much has your present hearing aid(s) changed your enjoyment of life?

$$
\text { worse no change slightly better quite a lot better very much better }
$$




\section{Appendix B}

Questions on perceived service quality

Questions on technical functionality of the instruments
1. How satisfied were you with the way the staff received you before your first visit?

2. How satisfied were you with the information and help you received at the visits?

3. To what extent did you perceive yourself as a participant in the fitting procedure?

4. To what extent did you have the possibility to decide on unilateral versus bilateral fitting?

5. To what extent did you experience that your audiologist listened to you and your wishes?

1. Does it happen that the sound level of your present hearing aids becomes unacceptably loud?

2. Does it happen that your present hearing aids howl or whistle when in place?

3. How satisfied are you with the sound quality of your present hearing aids?

4. Have your present hearing aids been of help when talking in noisy environments or when many talk people talk simultaneously? 